\title{
¿De qué hablamos cuando hablamos de izquierda hoy?
}

\section{What do we mean when we talk about the left today? Hugo Quiroga}

Hugo Quiroga es politólogo, investigador del Consejo de Investigaciones de la Universidad Nacional de Rosario y profesor de Teoría Política de la misma Universidad y de la Universidad Nacional del Litoral, Argentina.

E-mail: haquiroga@arnet.com.ar

\section{resumen}

El artículo analiza el significado que reviste hoy el término izquierda en el mundo y, de manera particular, en América latina, luego del fracaso de los proyectos revolucionarios, del colapso de los países del Este, y de la crisis de la socialdemocracia. Hay un dato histórico fundamental en la realidad de los Estados latinoamericanos: la democracia electoral ha encontrado consenso en todos ellos. En este contexto, se ha señalado reiteradamente el ascenso de la izquierda en la región. El texto señala que la nueva izquierda latinoamericana, que se denomina a sí misma posneoliberal, podría ser calificada como izquierda antineoliberal, y que es el resultado, entre otras cosas, del fracaso del neoliberalismo aplicado en la región y de la crisis de los partidos.

\section{summary}

The article analyzes the meaning that redresses today the term left in the world and, in a particular way, after the failure of the revolutionary projects, the collapse of Eastern Europe, and the crisis of social democracy. There is a fundamental historical fact in the reality of Latin American States: electoral democracy has found consensus on all of them. In this context, the ascent of the left side has distinguished itself repeatedly in the region. The text indicates that the new Latin American left, which calls itself posneoliberal could be described as antineoliberal left, and that is the result, among other things, of the failure of neoliberalism implemented in the region and the crisis of the parties.

\section{palabras clave}

izquierda / neoliberalismo / democracia / capitalismo / república

\section{keywords}

left / neoliberalism / democracy / capitalism / republic 
Hay un dato histórico fundamental en la realidad política de los países latinoamericanos: la democracia electoral ha encontrado consenso en todos ellos. En 2010, ningún Estado de la región está gobernado por otro principio que no sea el electivo. Con todos sus contrastes, matices y déficit, es un hecho novedoso y alentador para América latina que el proyecto democrático, basado en el sufragio universal y la competencia política, sea el modo de vida elegido por gobernantes y gobernados, luego de una historia repetida de fracasos y de largos períodos de discontinuidad institucional. Los avances en la cultura política expresan en el entendimiento colectivo de que un poder democrático (legal y legítimo) se instituye a través de la elección de los gobernantes por los gobernados.

Con sus altibajos, se ha resuelto el conflicto primordial de toda sociedad, la sucesión del poder en términos pacíicos. Es cierto que los desafíos son gigantescos cuando hay que enfrentar niveles muy altos de pobreza, exclusión, discriminación (muchos de ellos generados en el marco de la vida democrática), y formas muy devaluadas del Estado de derecho. Las contiendas más hostiles a esa regulación pacífica son las que derivan del propio orden político, sobre todo cuando los hombres se dividen a favor o en contra de la democracia. En efecto, la primera controversia que divide a las democracias inestables como las nuestras es la referida al traspaso del poder político. La historia latinoamericana fue tumultuosa en este sentido.

Bajo ese telón de fondo, se ha señalado de manera reiterada el ascenso de la izquierda en la región, principalmente en el Cono Sur. La noticia principal ha sido, pues, el denominado "giro a la izquierda" de varios de sus gobernantes: Hugo Chávez, en Venezuela; Evo Morales en Bolivia; Luis Inacio Lula da Silva, en Brasil; Tabaré Vázquez y José Mujica, en Uruguay; Ricardo Lagos y Michelle Bachelet, en Chile, Néstor Kirchner y Cristina Kirchner, en Argentina; Fernando Lugo, en Paraguay; Rafael Correa, en Ecuador; Daniel Ortega, en Nicaragua; Mauricio Funes, en El Salvador.

A grandes rasgos, lo que se descubre en ese amplio espectro ideológico son experiencias diferentes y concepciones dispares acerca del modo de entender lo que puede ser una alternativa de izquierda. El nacimiento de una nueva izquierda (o progresismo para algunos) no ha dado lugar a un sujeto político-ideológico de izquierda alternativo (o, para usar un término en desuso, a un sujeto histórico), ni a un recambio utópico, tras la caída del Muro de Berlín, a pesar de las reorientaciones progresistas de algunos de los gobernantes latinoamericanos.

En rigor, la diversidad ideológica y política distingue hoy a América latina, gobernada por líderes que se reconocen como integrantes de familias políticas diversas: de izquierda, de derecha, de centro. Lo significativo de este proceso es que el continente ha ingresado en el universo del juego electoral, que implica la idea de igualdad política, la competencia pacífica por el poder, y la constitución de un mapa pluralista, sin olvidar del golpe de Estado contra Manuel Zelaya, presidente de Honduras, en junio de 2009.

Existen, al menos, dos maneras (complementarias) de presentar la cuestión sobre el posible giro a la izquierda de los gobiernos latinoamericanos. La primera, ha sido destacada por Alain Rouquié en una entrevista en la que se le preguntaba ${ }^{1}$ : 
"¿Qué tipo de izquierda es la que está gobernando nuestros países”? Su respuesta fue: "Es cierto que hay muchos presidentes con un perfil de izquierda o centroizquierda, pero yo no veo muchos gobiernos de izquierda"; y enseguida agregaba: "Pero cuando se habla de un giro a la izquierda, que no lo hubo en México ni en Colombia, hay que ver más allá de los presidentes". La segunda, se refiere al contenido y alcance de las políticas públicas de izquierda, connotadas por el "estatismo", lo que implica analizar si las mismas han superado los intentos de redistribución compensatoria, propuestos por una vieja izquierda reformista.

El interrogante, entonces, que nos atrapa e inquieta es sobre lo que se entiende hoy por gobiernos de izquierda en Latinoamérica, cuando ha quedado atrás el proyecto de conquista revolucionaria del Estado y de destrucción del capitalismo. Sin duda, la pregunta excede a las izquierdas de nuestra región; ella remite a una crisis de ideas y a una crisis de proyecto de la izquierda en el mundo que no logra formular una alternativa a las transformaciones producidas en el orden político, económico y cultural de nuestras sociedades, por el diseño hegemónico del liberalismo económico (denominado comúnmente, y así lo utilizaremos, neoliberalismo).

\section{La tensión entre democracia y capitalismo global}

Las complejas sociedades en las que vivimos no pueden ser pensadas solamente en términos de teoría democrática. En este sentido es oportuno recordar lo que desde hace tiempo viene advirtiendo Robert Heilbroner (1996: 128) sobre la naturaleza capitalista de las sociedades que acostumbramos a describir como únicamente democráticas. Los latinoamericanos, afortunadamente, descubrimos en los últimos años a la democracia como orden político (después de dejar atrás largos períodos de dictaduras militares), pero sin prestar demasiada atención al capitalismo como orden económico-social, acaso más preocupados por entender, ante la presión de una fuerte corriente internacional, el libre funcionamiento de una parte de ese orden: el mercado.

La experiencia internacional ha demostrado que la democracia únicamente se ha desarrollado en el ámbito de las economías capitalistas. Sin embargo, el capitalismo ha sobrevivido, en lugares y momentos históricos diversos, sin la presencia de la democracia. A partir de esto, se pueden esbozar dos cuestiones. La primera, recordar la distinción básica señalada por Fernand Braudel: capitalismo y mercado no son la misma cosa. La confusión se origina, según Lindblom (1999), porque bajo los auspicios del capitalismo el mecanismo del mercado se convirtió en un organizador en gran escala de la vida económica. La segunda nos lleva a tener presente que la democracia no siempre triunfa en las economías de mercado, en algunas fracasa. ¿Cuál es la explicación? En la observación de Heilbroner (1990: 109-110), carecemos de una teoría general que nos dé una respuesta a ese interrogante.

Luego del fracaso de los países comunistas, la democracia y el mercado se quedaron sin rivales. Es innegable que la economía de mercado se ha impuesto y que la democracia parece expandirse en el mundo. Al mismo tiempo que los proyectos de ajuste estructural de los años ochenta motorizaban una economía abierta, se clausuraba el ciclo de las economías dirigidas. No obstante, lo que se ha puesto 
en claro en los años noventa son los límites y riesgos de una estrategia económica basada en la dinámica exclusiva del mercado. De ahí el intento de recuperación del Estado. Las consecuencias económico-sociales del ajuste neoliberal ortodoxo han favorecido el giro hacia una mayor participación del Estado, aunque el mismo no alcance los niveles de antaño. ${ }^{2}$ A pesar de los imprescindibles intentos de reconstitución del Estado, como ocurrió en algunos países de Europa y en América latina, no hay probabilidades de retorno a las antiguas formas de proteccionismo.

No obstante, la actual crisis financiera y económica mundial puso nuevamente de manifiesto la función del Estado frente a las disfuncionalidades de la economía, como ya había acontecido en el último cuarto del siglo XIX y en la crisis internacional de 1929. Tras el colapso de la Unión Soviética, Estados Unidos se reafirma como el país más poderoso del mundo, pero han surgido otros gigantes en la economía mundial: China, India y Brasil. En el nuevo contexto internacional, el dilema de la izquierda es saber cómo enfrentar y superar los desequilibrios estructurales del capitalismo, la pobreza extrema, con los recursos de una teoría keynesiana disminuida y un modelo de seguro social (de orden bismarckiano) debilitado, en la era de la sociedad del conocimiento.

El proceso de globalización, con sus sorprendentes innovaciones científicas y tecnológicas, es la causa y efecto de una profunda reorganización de la economía y la sociedad. Tal proceso de mundialización de la producción y la distribución, ha modificado, a la vez, las relaciones de poder entre la esfera pública y la privada. Así, el Estado-nación y los actores políticos, sin expresión transnacional como el capital, tienen dificultades para coordinar la economía nacional que funciona como parte de un sistema integrado a nivel mundial. El fenómeno de la globalización obliga a la izquierda, entonces, a repensar la relación entre democracia y capitalismo.

El problema es que la democracia y el capitalismo establecen diferentes sistemas de poder, basados en valores casi opuestos: la igualdad y la ganancia. Sin embargo, han podido convivir. El capitalismo genera desigualdades que la democracia, como fuerza igualadora, debe corregir. Este viejo problema, que dio lugar -anclado en el marco del Estado nacional- a una tradicional forma de relación entre economía y política, sufre hoy el desafío de un sistema de producción integrado a nivel internacional. La globalización del capitalismo pone en entredicho el rol tradicional del Estado y la política, y por ende, el papel de la democracia como lugar de convergencia entre igualdad y libertad. ¿Cuál es el espacio de poder que conservan las democracias locales en este proceso de globalización económica?

Aunque las democracias contemporáneas parecieran no disponer de la fuerza necesaria para torcer el rumbo de ciertas tendencias disgregadoras de la economía internacional, podrían, sin embargo, contrarrestar en sus propios espacios los efectos perniciosos de la lógica de la producción actual, como son el crecimiento con desempleo estructural y el aumento de la pobreza. A pesar del incontenible fenómeno de la globalización económica, no han desaparecido completamente los medios que dispone el Estado democrático para retener en sus manos la palanca de la redistribución social, instrumento válido para atenuar las profundas desigualda- 
des tan presentes en nuestras sociedades. El principio de redistribución compensatoria debería ser la obra directa de la democracia, cimentada en instituciones justas, y en políticas públicas socialmente satisfactorias. Pero esta tarea, aunque imprescindible, es insuficiente a la hora de ofrecer una alternativa de izquierda a las desigualdades globales, a la desigualdad distribución del poder y la riqueza. $L a$ compensación no es todo, hace falta más imaginación y creatividad para salir de una línea política defensiva.

En palabras de Walzer (2010: 118 y 125), uno de los requisitos de la justicia distributiva es una democracia fuerte, y ella exige que el poder político esté ampliamente disponible a los ciudadanos. El Estado debe responder a las necesidades socialmente reconocidas de sus miembros. En esta perspectiva, es dable propiciar la idea de un Estado-prociudadano, en lugar de un Estado-promercado, un Estado democrático de derecho que revalorice la relación con los ciudadanos, allanando el camino para que alcancen por ellos mismos sus objetivos, sin esperar todo del Estado. Es una manera, además, de restringir el poder del Estado paternalista, de promover a los ciudadanos como participantes del espacio público y vigorizar las capacidades individuales en el desarrollo de emprendimientos comunes. Un Estado, en fin, que abra paso a la constitución de proyectos comunitarios destinados a recuperar espacios de autonomía para beneficiar la libre asociación de los ciudadanos orientados a mejorar su calidad de vida, a obtener bienes sociales, y a acortar la brusca distancia entre representantes y representados (Quiroga, 1995: 151). Volviendo a Walzer, así como se "protegió a las instituciones de la sociedad civil frente al poder del Estado, tanto esas instituciones como el propio Estado deben ser protegidos frente a ese otro nuevo poder que surge del interior mismo de la sociedad civil: el poder de la riqueza" (Walzer, 2010: 97-98).

Si la democracia y el capitalismo se han quedado sin oponentes, y van a continuar conviviendo, es más necesario que nunca recuperar la iniciativa intelectual y moral para pensar bajo nuevos términos y con otros instrumentos el enlace entre economía y política. El desafío es saber cómo compatibilizar la lógica de la democracia con la lógica del capitalismo en la construcción de una sociedad más justa. Los gobiernos democráticos deben evitar que el orden capitalista obligue a la sociedad a convivir con desigualdades inaceptables. Por consiguiente, las exigencias del capitalismo globalizado y la realización del principio de igualdad de la democracia deben tener su punto de encuentro, y de equilibrio, en la acción de políticas públicas satisfactorias, que democraticen la economía. En un mundo globalizado sólo caben estrategias que contemplen políticas de alcance internacional. Si la reorganización de la economía y la sociedad operan a nivel mundial se requiere, por tanto, de políticas supranacionales. Precisamente, el sentido de la acción política sería la de establecer una conexión adecuada entre el fenómeno de la mundialización y las diversas realidades nacionales.

\section{La crisis de identidad de las izquierdas}

La identidad de la izquierda más influyente en nuestros días, la socialdemocracia, entró en crisis en el momento en que se produjo la ruptura del orden econó- 
mico keynesiano y el resquebrajamiento del Estado de bienestar, muy cuestionado por el liberalismo económico ortodoxo. Los logros fundamentales de esta izquierda de posguerra (aunque su origen sea muy anterior) fueron la creación de un sistema de bienestar y la preservación de tasas muy altas de empleo. Pero en su acción de gobierno se quedó sin políticas efectivas para hacer frente a la crisis estructural del capitalismo de fines de los años setenta y debió adoptar interpretaciones que no formaban parte de su universo ideológico, de corte monetarista, neoliberal: la reducción del gasto público, la disminución de la intervención del Estado, las privatizaciones, la liberalización de los mercados, la apertura económica, y la atenuación del poder de los sindicatos. El perfil de esta izquierda se resintió. De ahí la era que se inició con Thatcher y Reagan, en Inglaterra y los Estados Unidos, que se trasladó a nuestra región, si bien se pueden observar, con anterioridad, ciertos avances monetaristas que vinieron de la mano de los militares, como en la Argentina de 1976.

En consecuencia, en los años ochenta, la izquierda socialista retrocede en los ámbitos político, económico y cultural, frente al dominante discurso del neoliberalismo. A mediados de los años noventa, Pierre Rosanvallon (1995) tomaba nota de la crisis de la socialdemocracia europea y del fracaso de pretender cambiar la sociedad mediante los impuestos a los ingresos como dispositivo fundamental de las políticas reformistas. En lugar de una "revolución social política", la socialdemocracia, escribía Rosanvallon, soñaba con una "revolución social fiscal". En su concepción, los derechos sociales tradicionales se volvieron inoperantes para tratar el problema de la exclusión social y el desempleo de largo plazo, al transformarse en simples "derechos de desembolso". El Estado de bienestar clásico, pasivo, se transformó en una "máquina de indemnizar", en un Estado de bienestar "compensador". Tal vez es hora de explorar nuevas formas de solidaridad para reintegrar con plenos derechos a los excluidos, mediante la reformulación de los viejos métodos de gestión de lo social. Con un nuevo enfoque político-filosófico, la redistribución fiscal y la "nueva solidaridad", organizadas por un "Estado de bienestar activo", tendrían que dar forma y encarnadura a un nuevo derecho social: el derecho de "inserción".

Con todo, las más diversas izquierdas del mundo siguen pensando todavía en la redistribución compensatoria a través de los impuestos y el gasto público social, como vía alternativa a la abandonada teoría de la revolución de Marx, que presuponía la lucha de clases, la abolición del Estado y los mercados, fuentes fundamentales de alienación de las sociedades modernas. En el pensamiento de Marx, no hay espacio para el Estado de bienestar (activo o pasivo), ni para las políticas compensatorias (sería la forma más eficaz de "domesticar" a la clase obrera), porque el Estado siempre oprime: es violencia concentrada de una clase sobre otra.

En la opinión de Dahrendorf (2006: 211-215) (un liberal político no conservador), la revolución de 1989 no sólo puso fin al extravío del comunismo sino que también fue la demostración del agotamiento de la vitalidad del proyecto socialdemócrata. La globalización, como nueva fuerza productiva, terminó con la obra socialdemócrata y se abrieron nuevas tareas para la política y la sociedad. Así 
como el siglo XIX fue el siglo del liberalismo, el "breve" siglo XX fue el siglo socialdemócrata.

Como ha sido expresado, el otro componente central del amplio universo de las izquierdas (el eurocomunismo, los partidos comunistas) se desmorona frente al colapso de los países del Este. La izquierda ha quedado desconcertada, en un caso, y desarticulada, en el otro. La tradición comunista, heredera de la revolución de octubre de 1917, ha prácticamente desaparecido de Europa; su número de votantes se ha reducido considerablemente. Los partidos que representaban esta tradición, moderaron su perfil, y buscaron recomponer su imagen hasta llegar a renunciar al nombre de "partido comunista", para abrir un escenario postcomunista acorde con la nueva época, sin una clara identidad política. En rigor, ¿cuánto hay de responsabilidad del capitalismo y cuánto de los propios errores de esas izquierdas en este proceso?

En América latina coexisten, al menos, dos tradiciones de izquierda. Una que se podría denominar genéricamente nacional y popular (distante del liberalismo político y económico) y, la otra, de corte socialdemócrata (próxima al liberalismo político y distante del liberalismo económico). Son dos matrices políticas muy diferentes, que muy esquemáticamente se pueden referenciar en las nociones de pueblo y ciudadanía. Dicho de otra manera, dos concepciones diferentes de la política que abren las puertas a dos fuentes de legitimación del Estado democrático, que aparecen algunas veces compitiendo entre sí, cuando, en rigor, no deberían ser contradictorias en el momento de tomar decisiones: la legitimidad popular y la legitimidad constitucional. El poder político, avalado por el principio de la mayoría, no es la única fuente de legitimidad de las decisiones, porque el ejercicio de ese poder no es ilimitado y está sujeto al contrato constitucional y sus derechos fundamentales, que son también fuente de legitimidad de las mismas.

No obstante, la vía reformista de transformación de la sociedad es el punto común entre esas dos tradiciones, basada en el principio de posibilidad de alcanzar la justicia social desde dentro del sistema capitalista. La propuesta nacional-popular con su énfasis antiimperialista, y la corriente socialdemócrata que coloca el acento en un cambio social en el marco de una democracia social y participativa. La que ha prevalecido históricamente en nuestra región es la primera.

En las décadas de los sesenta y setenta surgieron variantes revolucionarias que apostaron a la lucha armada, de carácter anticapitalista, desde perspectivas diferentes. Aunque la estrategia común fuera el combate armado, algunas recibieron la influencia del modelo nacional-antiimperialista (que luchaba contra la dependencia y la inserción periférica de nuestros países en el mundo capitalista) y, otras, en cambio, con pretensiones más universalistas, de inspiración marxista, se apoyaron en el molde de referencia provisto por las revoluciones soviética, china y vietnamita. El poder de la palabra fue reemplazado por el poder del fusil ("el poder nace del fusil”, simbolizaba Mao Tsé-Tung, máximo líder de la revolución china).

La violencia política fue, sin duda, una marca de época. El tiempo revolucionario se inició, dicho en grandes trazos, con la revolución cubana de 1959, continuó con la presencia del "Che" Guevara en Bolivia, la revolución sandinista, el Frente 
Farabundo Martí, los movimientos guerrilleros en la Argentina, Uruguay y, más tardíamente, el frente armado en Chiapas, como representante de poderes locales. La "violencia racionalizada" (en tanto medio para obtener un fin) se propone, escribe Claudia Hilb, como el sustituto de la política, ese tipo de violencia aparece como una manera extrapolítica de intervenir en los asuntos comunes, y es a la vez destructora de la acción pública (Hilb, 2003). En efecto, la política concebida como ejercicio de la violencia, separada de los ciudadanos y la esfera pública, es el contramodelo de una política republicana y democrática.

El debate central que atraviesa y diferencia estas múltiples izquierdas es la contraposición entre "reforma o revolución". La consigna que resume la posición de la izquierda revolucionaria es "liberación o dependencia". En un universo viciado por la ilegitimidad del traspaso del poder (dictaduras civiles y militares, revolución y contrarrevolución), se pueden observar tres rasgos distintivos de un clima de época: la violencia política, la idea de revolución y la desvalorización de la democracia. En el horizonte de la izquierda revolucionaria se pensaba alcanzar, como estado final, un orden político sin conflicto (el socialismo) por medio de la violencia liberadora. En aquellos años donde parecía no existir una alternativa clara y concluyente entre las que poder elegir, la democracia carecía de significado positivo y se presentaba más bien como una posibilidad vacía. No simbolizaba un valor constitutivo, esto es, un valor compartido y aceptado por la mayoría de los ciudadanos latinoamericanos.

Finalmente, ni las organizaciones revolucionarias ni los partidos reformistas resultaron triunfantes en la región, en la que se abrió un nuevo ciclo de regímenes militares, especialmente en Sudamérica, en la década del setenta. Dictadura y democracia aparecen como dos momentos históricos relevantes en el plano de la experiencia colectiva, en el que cada uno deja su huella, sus marcas, en la cultura política. En 1980 ocho de las diez naciones sudamericanas estaban gobernadas por militares. Las únicas excepciones las constituían Colombia y Venezuela. Diez años más tarde, en 1990, la situación se modificó completamente con el retorno masivo de nuestros países a la democracia. La era civil asomaba en el horizonte del Cono Sur, luego del retiro de las Fuerzas Armadas a sus cuarteles. De a poco, los Estados latinoamericanos se fueron desmilitarizando y los sistemas políticos se volvieron completamente civiles, dejando atrás el antiguo formato de un sistema político pretoriano.

En menos de una década se produjeron dos cambios fundamentales en el orden colectivo de Latinoamérica, que modificaron su perfil, tanto en el plano económico como en el sistema político. En breve, nos encontramos con una situación paradójica. Una combinación de neoliberalismo con una democracia electoral atravesada por una crisis de confianza, y la descomposición o debilitamiento del sistema de partidos.

Las transformaciones económicas neoliberales dieron por tierra con una economía dirigida. La nueva orientación planteada obedeció a la vulnerabilidad de nuestras sociedades que recibieron el impacto de un peculiar contexto internacional, que resultó fuente de motivación y de condicionamiento, al mismo tiempo. En tres 
horizontes simultáneos se proyectaron los objetivos del programa neoliberal que procuró instalar una economía de mercado: la liberalización de la economía (apertura comercial y libre circulación del capital), la reforma del Estado (privatización de las empresas públicas), y la desregulación de los mercados (especialmente el mercado de trabajo). Con mayor o menor énfasis en las argumentaciones, con diferencias prácticas y conceptuales, existió un común denominador en la caracterización de la resolución de la crisis del capitalismo juzgada como universal: la apertura económica, las privatizaciones, las desregulaciones y el equilibrio fiscal.

A la vez, un catálogo de acontecimientos fue erosionando el sistema político de muchos países de la región, a pesar, como dijimos, de que la democracia electoral había comenzado a reafirmarse a partir de la década de los ochenta. La descomposición del sistema institucional tradicional (en Venezuela, Bolivia y Ecuador), la fragmentación del sistema de partidos (en Argentina), el profundo malestar de los ciudadanos con la representación en numerosos países, que cuestiona la relación entre gobernantes y gobernados en ocasión del poder. El factor central que los impulsa es la crisis de confianza que afecta a representantes y representados. En este contexto se ha extendido el poder de la calle, los movimientos informales, más organizados o menos organizados, que cuestionan y expanden, al mismo tiempo, la acción política tradicional. Los movimientos informales son la otra cara de la vida democrática, porque ellos nacen de las propias tensiones de la democracia, y actúan en un ámbito extraparlamentario que tiene lugar fuera de la esfera oficial del poder. En este trasfondo se actualiza el carácter conflictual de la política.

Con este escenario político tan oscilante, y con desigualdades sociales vergonzantes, los partidos de la denominada nueva izquierda latinoamericana, y los gobernantes que se reconocen en ese espacio, tienen que asegurar la armonía social, el crecimiento integral y las libertades públicas. El enorme desafío es, indisociablemente, teórico y práctico.

\section{Desbrozando el camino}

La izquierda contemporánea pasa por un mal momento, no ha podido reconstituirse a partir de un ideario novedoso. Representa más bien un cuerpo de pensamiento y de proyecto en crisis, y debería entender la especificidad de la época en la que vive, y extraer conclusiones de su pasado y de sus funciones. Quizá problema se halle en la ausencia de una alternativa real de poder. Ya no puede, como antes, ser identificada con el Estado, ni con el movimiento obrero. Hasta la primera mitad de los años setenta "izquierda y Estado de bienestar" e "izquierda y movimiento obrero" eran términos intercambiables.

Por un lado, el estatismo, con las políticas de distribución compensatorias, es revelador de las insuficiencias que no permitieron contrarrestar los desequilibrios sociales y las situaciones de desarraigo y discriminación. Más que una propuesta alternativa innovadora, el estatismo nacionalista, es una respuesta correctora de las asimetrías e irregularidades del neoliberalismo. Por el otro, la clase obrera que trabaja manualmente se ha reducido hasta una media de la cuarta parte de la población activa y se ha visto superada en todas partes por los trabajadores 
terciarios (Anderson, 1994: 91). La economía del conocimiento ha transformado nuestras propias vidas y trabajos. Hasta hace no tanto, más de la mitad de la población trabajaba en la producción o en la agricultura. La clase obrera industrial tradicional ha disminuido sustancialmente. A comienzos del siglo XXI, en los países occidentales, la proporción de la población que trabaja en esos sectores no alcanza el 20\%, disminución que se origina por los cambios tecnológicos y la globalización del comercio (Giddens y Hutton, 2001: 18).

La renovada "Tercera Vía", impulsada principalmente por Anthony Giddens, que buscó reemplazar "el desafío al capitalismo de la vieja socialdemocracia por una identificación con el desarrollo capitalista hasta el límite de exaltar en el capitalista al agente del progreso" (Cheresky, 2001: 43), fue incapaz, a nuestro entender, de crear un ideario teórico y práctico de izquierda alternativo. Como lo han advertido numerosos autores, el capitalismo global ha producido un divorcio entre poder y política que, con anterioridad, coincidían en el territorio del Estadonación. El poder se ha vuelto extraterritorial y no hay una política de esa amplitud. La actual crisis financiera mundial no hizo más que corroborar la desregulación del capital financiero. Una cantidad cada vez mayor de decisiones se toma en los organismos internacionales y en las corporaciones económicas internacionales, que no son territoriales ni democráticas.

En América latina más que un giro a la izquierda lo que se reproduce, sobre todo en ciertos países (Venezuela, Bolivia, Ecuador), es el resurgimiento de una visión estatista, nacionalista y nativista de la política, resultado, entre otras cosas, del fracaso de las políticas neoliberales aplicadas en la región y de la crisis de los partidos. El eje del "núcleo duro" de la nueva izquierda latinoamericana es la lucha contra el neoliberalismo, su enemigo principal, sin muchos matices ni creatividad. Esa fuerza política, que se denomina a sí misma posneoliberal, podría ser calificada como izquierda antineoliberal. Pero los valores y proyectos de izquierda no pueden establecer sus diferencias políticas en torno a un único adversario, sino que deben estar integrados en una estrategia programática progresista, que incluya la complejidad de los problemas actuales. A título ilustrativo, la integración latinoamericana está en los hechos paralizada por los conflictos entre los Estados y por concepciones opuestas entre los gobernantes.

Sin embargo, hay fenómenos relevantes y novedosos resultado del principio de legitimidad democrática. En Brasil, por primera vez un obrero, Lula, es votado por las clases populares y nombrado presidente en dos oportunidades. En Bolivia, un descendiente de los pueblos originarios, Evo Morales, asume también por primera vez la presidencia de la nación. Ello denota un cambio positivo en la cultura política de esos pueblos. Ambos dirigentes pertenecen a familias de izquierda diferentes, gobiernan con coaliciones distintas, y sus políticas públicas son disímiles.

La izquierda latinoamericana no pudo escapar de los efectos de la crisis de identidad de la izquierda europea y de la falta de una teoría global de la sociedad, luego de la crisis de la teoría económica keynesiana, del colapso de los países del Este y de los cambios de condiciones operados en la década del 80 con la hegemonía del neoliberalismo y del imperio de la globalización. Esta situación no puede sosla- 
yarse hoy cuando se piensa en la reconstrucción de una opción política progresista. Pero, además, como una diferencia fundamental, esa izquierda no tiene un pasado común, pues alberga en su interior posiciones diferentes y hasta encontradas, sobre temas centrales de toda comunidad política. Esta falta de historia en común, que obedece a matrices políticas distintas, impone una fuerte limitación.

Otro de los temas centrales del debate en América latina que sólo mencionaremos aquí (aunque se trate de un fenómeno mundial) es el surgimiento de la "antipolítica". Nos referimos con ello al sentido de "la política de la antipolítica": se hace política sin que se la asuma como tal. En un tono polémico, Alain Rouquié entiende que de la crisis de los partidos emanan los movimientos antipolíticos, que nacen fuera de la vida política, como los casos de Ollanta Humala, en Perú; Evo Morales, en Bolivia (muy curioso, agrega Rouquié, porque el MAS representa un "partido antipartido" con un discurso antiparlamentario y antipolítico); o en la Argentina, cuando se coreaba masivamente en las calles "que se vayan todos"; o Chávez, en Venezuela, que erige su popularidad sobre el colapso de los partidos, pero se cuida mucho de no crear un partido (Rouquié, 2006).

En un momento histórico muy diferente (el de la disidencia en el bloque soviético), bajo un régimen totalitario de partido único, Václav Havel se opone a la política como "técnica de poder" (esto es, su reducción a simple técnica de dominación y manipulación), y cree, en este caso, que la "política antipolítica" es posible, pero la política "desde abajo", la política del hombre y no del aparato. ${ }^{3}$

El republicanismo, por su parte, implica una forma determinada de orden político, que requiere de la participación activa de los ciudadanos en la organización de los asuntos públicos. Al enriquecer la vida democrática, y dar vida a la ciudadanía, la concepción republicana de la política es incompatible con la "política de la antipolítica". Por su propia naturaleza, la política no se circunscribe a una mera actividad instrumental. La política, al responder a una necesidad de la vida social, facilita y armoniza los diversos intercambios y relaciones posibles entre los miembros de una sociedad. Por tanto, una de las premisas de la política republicana es el espacio público y la ciudadanía. Sin ciudadanos, ni esfera de deliberación (institucional e informal), no existe la política.

Las fronteras que separan la izquierda de la derecha, que ya no circunscriben como antes familias políticas muy diferentes, están demarcadas por valores democráticos republicanos. Sin pretender agotar ninguna lista, hay valores colectivos fundamentales que están presentes en un pensamiento de la izquierda democrática: libertad política, igualdad social, tolerancia, diversidad, disenso, igualdad de género, ley, institución, ambiente, interés nacional, integración regional, deliberación pública, división de poderes, participación y control de la ciudadanía, vida asociativa amplia, que deben regir el funcionamiento de la vida común, y ocupar un lugar relevante en la agenda de gobierno. Asimismo, una política de izquierda democrática republicana no sólo debe atender la inmediatez de los intereses, las situaciones puntuales, las expectativas más próximas de los electores, sino que también debe otorgar sentido al mundo común mediante la formulación de proyectos que engloben al conjunto, y tengan en cuenta el interés público. En otras pala- 
bras, que la política no se agote en la gestión burocrática cotidiana de los asuntos gubernamentales. La política no es un hacer simplemente instrumental, el riesgo es que la izquierda puede ser tan pragmática como la derecha. El "pragmatismo progresista" es una variante del progresismo político.

Uno de los desafíos de la izquierda latinoamericana es su redefinición en función de nuevos (y viejos) problemas, sin desconocer los actores existentes, en cuyo espacio debe coexistir lo propio y lo extraño. ¿Cómo forjar una identidad política que ya no puede ser, como antes, identificada completamente con el Estado o con la clase obrera? ¿Cómo pensar una izquierda de largo plazo, liberada del ideal de la revolución anticapitalista? La izquierda debe lidiar hoy con su propia historia, pero también con la declinación del sistema de partidos, con los cambios en la representación, con la crisis de confianza que afecta a gobernantes y gobernados, con la personalización de la opción electoral, con la mediatización de la política, con el capitalismo global, factores todos que aumentan la complejidad de la convivencia pública.

Antes que recurrir al viejo modelo de intervencionismo de lo que se trata es de averiguar cómo se construye una "economía de mercado coordinada" (diferente tanto de una economía regulada por el Estado como de una economía de mercado neoliberal) en la cual la regulación social repose en una visión integral y articulada entre la acción estatal, la economía de mercado, y la acción pública de los ciudadanos. A riesgo de insistir, en este nuevo escenario hay que revisar la relación entre economía y política.

En los últimos años se ha renovado el interés por el republicanismo, que hasta hace poco era considerado por muchos como una tradición de pensamiento anacrónica u obsoleta, casi inviable para la complejidad de las modernas sociedades democráticas representativas. En esta recuperación del republicanismo han desarrollado una labor destacada historiadores del pensamiento político y filósofos políticos como Pocock, Skinner, Dunn, Pettit, Viroli, Doménech, y otros, que han llamado la atención sobre la importancia de esta corriente de pensamiento, que aunque finalmente derrotada por el liberalismo, tuvo un peso considerable en la teoría política de la modernidad, desde Maquiavelo a Marx, pasando por Spinoza, la ilustración escocesa, y los teóricos de las revoluciones norteamericanas y francesa. Vale la pena destacar, por último, la interpretación de Lefort sobre la obra de Maquiavelo. Entre los fundamentos de la república está el concepto de igualdad, por eso para Maquiavelo es un régimen superior. A la vez, señala Lefort, al Estado le es necesario ser poderoso, y su potencia se mide por la adhesión que le da el conjunto de los ciudadanos. Un Estado poderoso es aquel en el que los ciudadanos son capaces de movilizarse para defender sus derechos de participar en los asuntos públicos (Lefort, 2010: 570-574).

En efecto, si es posible la recuperación del espíritu de la concepción republicana bien podría ser el fundamento de una visión renovada de la política para las democracias contemporáneas. Si bien hay versiones diferentes del republicanismo se puede encontrar un léxico común en las ideas de deliberación pública, libertad política, bien común, virtud cívica, participación activa de los ciudadanos en los 
asuntos públicos, rendición de cuentas. El ideal de autogobierno (o ejercicio colectivo y directo del poder) solo puede concebirse hoy en un molde más amplio de democracia, que exceda su plano político-representativo, para comprender la acción pública de los ciudadanos. En la tradición republicana, la democracia es un proceso de ampliación de la esfera pública. En otras palabras, la construcción de un espacio público común es la condición de realización de la democracia. Tanto la capacidad de construir procesos argumentativos como el intercambio de opiniones revitalizan a la democracia, y de ninguna manera niegan el momento de la decisión política. La democracia republicana ensancha, en definitiva, la base de la decisión política.

El republicanismo ha traspasado hoy el debate académico. Ha sido rescatado por los discursos de dirigentes de la izquierda y de la derecha. Una concepción republicana de izquierda, asentada en los cimientos del republicanismo clásico, puede brindar nuevas pistas para la acción política y ofrecer caminos alternativos de emancipación. Uno de sus desafíos principales es mostrar su capacidad de formulación de políticas públicas innovadoras que aborden los grandes problemas de la comunidad política real.

República y democracia no se oponen, son dos términos complementarios. Si la república tiene como objeto el interés público, la revalorización del espacio público y la participación activa de los ciudadanos, no le cabe otra opción que la de ser democrática, para instituir el gobierno del "gran número". La república democrática es un régimen de libertad e igualdad. Al tener siempre en vista el interés público, la democracia republicana exige el respeto de aquellas reglas y derechos que fija la Constitución, y que muchos gobiernos, de manera frecuente, tienden a violar. La tarea fundamental de dirigentes y ciudadanos es la construcción de una verdadera democracia republicana, lo que nos obliga a reforzar un debate común para analizar con precisión las causas que nos alejan de ella.

\section{Referencias}

1. A. ROUQUIÉ, "Por primera vez en décadas, la Argentina es hoy un país normal", entrevista realizada por Fabián Bosoer, Clarín, 12/11/2006.

2. Véanse las recomendaciones del Banco Mundial en su Informe de 1997: El Estado en un mundo en transformación, Washington, EE.UU.

3. Escribe Havel en 1984: "Soy partidario de una 'política antipolítica'. Una política que no es ni una tecnología del poder y una manipulación de éste, ni una organización de la humanidad por medios cibernéticos, ni un arte de la utilidad, del artificio y de la intriga. La política, tal como yo la comprendo, es una manera de buscar y de conquistar el sentido de la vida; una manera de buscar y proteger ese sentido; una política como moralidad practicada, como un servicio a la verdad, como preocupación por nuestro prójimo, preocupación esencialmente humana, que se rige por criterios humanos. Es una forma muy poco práctica en el mundo de hoy y difícilmente aplicable en la vida cotidiana. No obstante, yo no conozco otra alternativa mejor".

4. La expresión la tomamos de E. VERDIER. 


\section{Bibliografía}

P. ANDERSON (1994), "La izquierda europea", en Debats, diciembre, Valencia, Edicions Alfons El Magnánim.

I. CHERESKY (2001), "La influencia de Giddens en el debate socialdemócrata. Controversias en torno a la Tercera Vía", en Sociedad. № 17/18, Facultad de Ciencias Sociales, Universidad de Buenos Aires. R. DAHRENDORF (2006), El recomienzo de la historia. De la caída del Muro a la guerra de Irak, Buenos Aires, Katz.

A. GIDDENS y W. HUTTON (2001), "Conversaciones entre Anthony Giddens y Will Hutton”, en A. GIDDENS y W. HUTTON (eds.), En el límite. La vida en el capitalismo global, Barcelona, Tusquets Editores.

R. HEILBRONER (1996), Visiones del futuro, Barcelona, Paidós.

(1990), Naturaleza y lógica del capitalismo, Barcelona, Península.

C. HILB (2003), "La responsabilidad como legado", en C. TCACH (comp.), La politica en consignas. Memoria de los setenta, Rosario, Homo Sapiens Ediciones.

C. LEFORT (2010), Maquiavelo. Lecturas de lo político, Madrid, Trotta.

Ch. LINDBLOM (1999), Democracia y sistema de mercado, México, FCE.

R. MANGABEIRA UNGER (2010), La alternativa de la izquierda, Buenos Aires, FCE.

J. NATANSON (2008), La nueva izquierda. Triunfos y derrotas de los gobiernos de Argentina, Brasil, Bolivia, Venezuela, Chile, Uruguay y Ecuador, Buenos Aires, Debate.

J. PEÑA (2004), “Tiene futuro el republicanismo", en F. QUESADA CASTRO (Editor), Siglo XXI: ¿un nuevo paradigma de la política?, Barcelona, Anthropos-Universitat de les Illes Balears.

H. QUIROGA (1995), "Demos y Kratos. Nuevo encuentro con el concepto de democracia", en H. QUIROGA, La democracia que tenemos. Ensayos políticos sobre la Argentina actual, Rosario, Homo Sapiens Ediciones.

P. ROSANVALLON (1995), La nueva cuestión social. Repensar el Estado providencia, Buenos Aires, Manantial.

A. ROUQUIÉ (2006), "Las condiciones de la democracia", diálogo con Aníbal Jozami, en Archivos del Presente. Revista Latinoamericana de temas internacionales, $\mathrm{N}^{\circ} 42$.

E. SADER (2009), El nuevo topo. Los caminos de la izquierda latinoamericana, Buenos Aires, Siglo veintiuno-CLACSO.

M. WALZER (2010), Pensar políticamente, Buenos Aires, Paidós.

Recibido: 30/07/2010. Aceptado: 05/09/2010.

Hugo Quiroga, "¿De qué hablamos cuando hablamos de izquierda hoy?". Revista Temas y Debates. ISSN 1666-0714, año 14, número 20, octubre 2010, pp 21-34. 